\title{
Environmental arsenic exposure and risk of diabetes type 2 in Ron Phibun subdistrict, Nakhon Si Thammarat Province, Thailand: unmatched and matched case-controlstudies
}

This article was published in the following Dove Press journal:

Risk Management and Healthcare Policy

II April 2017

Number of times this article has been viewed

\author{
Kwanyuen Sripaoraya ${ }^{1,2}$ \\ Wattasit Siriwong' \\ Sumol Pavittranon ${ }^{2}$ \\ Robert S Chapman' \\ 'College of Public Health Sciences, \\ Chulalongkorn University, Bangkok, \\ ${ }^{2}$ Medical Life Sciences Institute, \\ Department of Medical Sciences, \\ Ministry of Public Health, Nonthaburi, \\ Thailand
}

Correspondence: Kwanyuen Sripaoraya Medical Life Sciences Institute, Department of Medical Sciences, Ministry of Public Health, 88/7 Tivanon Road, Muang District, Nonthaburi I I000,

Thailand

Tel +66850441977

Email kwanyuen.s@dmsc.mail.go.th
Background: There are inconsistent findings on associations between low-to-moderate level of arsenic in water and diabetes risk from previous epidemiological reports. In Ron Phibun subdistrict, Nakhon Si Thammarat Province, Thailand, a low level of arsenic exposure among population was observed and increased diabetes mellitus (DM) rate was identified.

Objectives: We aimed to investigate the association between determinants (including low-level water arsenic exposure) of DM type 2 risk among residents of three villages of Ron Phibun subdistrict, Nakhon Si Thammarat Province.

Materials and methods: Secondary data from two previous community based-studies, conducted in 2000 and 2008, were utilized. Data on independent variables relating to arsenic exposure and sociodemographic characteristics were taken from questionnaires and worksheets for health-risk screening. Water samples collected during household visit were sent for analysis of arsenic level at certified laboratories. Diabetes cases $(\mathrm{N}=185)$ were those who had been diagnosed with DM type 2. Two groups of controls, one unmatched to cases $(n=200)$ and one pair matched on age and gender $(n=200)$, were selected for analysis as unmatched and matched case-control studies, respectively. A multiple imputation technique was used to impute missing values of independent variables. Multivariable logistic regression models, with independent variables for arsenic exposure and sociodemographic characteristics, were constructed. The unmatched and matched data sets were analyzed using unconditional and conditional logistic analyses, respectively.

Results: Older age, body mass index (BMI), having a history of illness in siblings and parents, and drinking were associated with increased DM type 2 risk. We found no convincing association between DM type 2 risk and water arsenic concentration in either study.

Conclusion: We did not observe meaningful association between diabetes risk and the lowto-moderate arsenic levels observed in this study. Further research is needed to confirm this finding in the study area and elsewhere in Thailand.

Keywords: diabetes, arsenic exposure, case-control, Ron Phibun subdistrict, Thailand

\section{Introduction}

Epidemiological findings on a positive association between arsenic exposure and diabetes mellitus (DM) were evidenced in high arsenic-contaminated areas in Taiwan, India, and Mexico. ${ }^{1-4}$ However, the positive link between arsenic exposure and DM was also found in the low contaminated areas, although the results are not conclusive as in some cases and no association results were witnessed..$^{5-8}$ Some limitations from previous studies such as study design, exposure assessment, 
and application of suitable biomarkers (both markers of exposure and effect) lead to the need for more field studies that cover the limitations of the previous ones. ${ }^{5} \mathrm{~A}$ recent meta-analysis that was aimed to assess the link between arsenic exposure and DM risk reported an association between ingestion of arsenic and DM risk, though cautious interpretation of these results has to be made due to considerable heterogeneity of the 38 selected studies published during 1980-2014. ${ }^{8}$

The residents of Ron Phibun subdistrict, Nakhon Si Thammarat Province, Thailand, had been exposed to arsenic contamination in their environment for three generations. ${ }^{9}$ Since arsenicosis cases were first observed in 1987 , there were some efforts to reduce arsenic exposure such as continuous campaign aiming to replace usage of well water with tap and rainwater for household consumption and the closure of contaminated wells. ${ }^{9}$ However, there are still appreciable household water arsenic levels in three villages in the Moo Ban 2, 12, and 13, as evidenced by the levels of arsenic in toenails among 32 pregnant women, ranging from 0.1 to $68.63 \mu \mathrm{g} / \mathrm{g} .{ }^{10}$ During October 2000 to March 2001, Pavittranon et al conducted a cross-sectional survey on arsenic exposure. They measured 1) the arsenic level in consumption water in each household; 2) inorganic arsenic in morning urine of individuals; and 3) the urinary glucose level of 783 people living in village numbers 13 and 2 of Ron Phibun subdistrict, where unusually high environmental arsenic levels had been previously reported. ${ }^{11}$ Apart from using strip test for urinary glucose measurement, the outpatient cards (Outpatient Department [OPD]) at the Ron Phibun Hospital were reviewed to identify DM patients. Questionnaires were used to obtain all needed information, and it was found that $2.94 \%$ of participated population or $0.58 \%$ of total population of these two villages had $\geq 100 \mathrm{mg} / \mathrm{dL}$ of sugar level in urine. Until the year 2004, according to Ron Phibun Hospital's record, there were $177 \mathrm{DM}$ patients out of 24,477 people $(0.723 \%$ or 723 people per 100,000 people) in the Ron Phibun subdistrict. When compared to the Nakhon Si Thammarat DM provincial rate of 146.59 people per 100,000 people, as reported in the year 1999, the DM rate of Ron Phibun subdistrict was 4.9 times higher. Moreover, the 1996-1997 second national health survey report indicated that the DM rate among Thais was $0.147 \%$, whereas the rate in Ron Phibun subdistrict was $0.723 \%$. Thus, it led us to focus our study on the investigation of determinants (including low-level arsenic exposure) of DM type 2 risk in the study area described earlier.

\section{Materials and methods Data source}

Secondary data from two previous community-based studies in 2000 and 2008 were utilized in this study. Since the first case of arsenic poisoning was reported to public in Thailand in 1987, the most polluted areas identified were Moo (village) 2, 12, and 13 in the Ron Phibun subdistrict. Thus, these three villages were selected as the study area. For all analyzed socioeconomic information and sources of water that the individuals used for consumption, standardized questionnaires and worksheets for health-risk screening and water collection were used. For both years, the information of different water types (eg, municipal tap water, village tap water, well water, bottled water, rain water) came from questionnaires, whereas total arsenic concentration in each type of water sample collected from an individual's house was measured using graphite furnace atomic absorption spectrophotometry (GFAAS) and hydride generation atomic absorption spectrophotometry (HGAAS) at reference laboratories of the Department of Medical Sciences, Ministry of Public Health, Thailand. Melanosis or hyperkeratosis (as a potential marker of water arsenic exposure) was identified after skin examination of individuals by a specially trained nurse at the time of interviewing in the year 2000 study.

\section{Study setting}

Two case-control studies, one with unmatched controls and the other with pair-matched controls, were conducted to evaluate the associations between environmental water arsenic and diabetes risk. Both studies included the same 185 cases. A total of 200 controls were selected for the unmatched study. A total of 185 controls, matched with individual cases on age and gender, were selected for the matched study. In the authors' opinion, the opportunity to conduct studies with different designs strengthened the interpretation of analytical results.

Both cases and controls were males or females aged $\geq 35$ years and residents of Moo 2, 12, and 13 for $>1$ year. Cases were identified by medical record, according to the diabetes clinic of Ron Phibun Hospital, a community hospital in the Ron Phibun district area. Unmatched controls were selected randomly as a subsample of combined population of the three Moo Ban (Moo 2, 12, and 13) of the Ron Phibun subdistrict for $>1$ year.

\section{Demographic and water arsenic concentration variables}

Data on independent variables such as gender, age, body mass index (BMI), exercise, residency in different Moo Ban 
(Moo 2, 12, 13) and length of residence (years), history of illness of parents and siblings, smoking, drinking, observation of melanosis or hyperkeratosis, marital status, education, occupation (farmer, government officer or own business, and laborer and others), and motorcar ownership (reflecting economic status) were scrutinized for association with DM type 2 in the study area. Doing exercise in this study means exercising for at least 30 minutes per time and three times per week. We classified reporting DM, hypertension (HT), gout, chronic renal failure (CRF), myocardial infarction, stroke, chronic obstruction pulmonary disease (COPD), and paralysis or myocardial ischemia as having a history of illness in both parent and sibling categories.

Arsenic levels in drinking water, cooking water, and teeth brushing/bathing water were calculated by averaging measured levels in the water types that the subjects reported using for each of these applications. For example, if a subject reported using municipal tap water and well water for drinking in 2000, the arsenic levels in these two water types were averaged to give an estimated arsenic level in that subject's drinking water in 2000 . This procedure was used in deriving arsenic levels for each subject in 2000 and 2008 separately.

\section{Statistical analysis}

Since we had variables with missing data, levels of independent analytical variables were first imputed. Variables for which $>80 \%$ of values were missing were not imputed or included in analytical models. Data sets were imputed separately for the unmatched and matched case-control studies, using the multiple imputation (MI) method (SPSS version 22.0). To reduce uncertainty that could arise from occurrences of negative values after MI of continuous variables that had skewed distributions, the predictive mean matching (PMM; as an imputation method in the method subcommand of MI, SPSS version 22.0) was also used. ${ }^{12}$

A multivariable analysis model with unconditional logistic regression analysis for unmatched control and conditional logistic for matched control were used for association analysis whereby a significant association is identified when $p$-value is $<0.05$. In the conditional logistic regression, we used Cox models whereby the strata were the separate case-control pairs. Matching factors such as age and gender were not considered as independent variables in the conditional logistic regression models.

For association analysis, three modeling steps were made as follows. 1) For each of the fully imputed data set of unmatched and matched control groups, we first settled on sociodemographic variables to be used. These variables included being male (only unmatched control), age as of year 2008 (only unmatched control), BMI in the year 2008, exercise, living in different Moo Ban (Moo 2, 12, and 13; Moo 2 as reference), having a history of illness in parents and siblings, smoking, drinking, having either melanosis or hyperkeratosis, marital status, education level, year of residency in Ron Phi Boon, being farmer and being government official or owning business (being laborers and others as reference), and having motorcar (represent a better economic status). 2) To bring forward sociodemographic independent variables to subsequent models, we made three consecutive intermediate models for unmatched control and two models for matched control, whereby a cutoff point for $p$-value of 0.200 was used for selection of input variables to the next model. We finally selected eight and six sociodemographic variables for unmatched and matched analyses, respectively. 3) One model was constructed, both in unmatched and matched controls, to combine selected sociodemographic variables (eight for unmatched and six for matched control groups) with average arsenic concentrations in different water types and to combine with average arsenic concentrations in drinking water, cooking water, and teeth brushing/bathing water variables in 2000 and 2008.

\section{Ethics statement}

This study used secondary data from previous two studies. First, the European Union (EU) funded project (year 2000) under the Department of Genetic and Cellular Toxicology, Stockholm University, Sweden, whereby the project called "Selection of arsenical exposed populations and individuals in Ron Pi Boon district, Thailand" was created and performed as part of this big project by the Department of Medical Sciences. ${ }^{11}$ The second was the Thai government-funded project (year 2008) under the Department of Medical Sciences called "The investigation of association between low and moderate arsenic exposure and diabetes in Ronpiboon District, Nakorn Si Thammarat, Thailand" (Sripaoraya et al, unpublished data, December, 2008). The protocols for these studies were developed and received approval from the Ethical Committee on the Clinical Study in Humans, Department of Medical Sciences. Groups' informed consent was obtained, and each participating individual was asked to sign a consent form during these studies. The corresponding author was the main investigator of these projects.

\section{Results}

The associations between the sociodemographic variables and DM type 2 risk of both unmatched and matched control groups are presented in Table 1. We found that older 
Table I Association analysis between DM type 2 risk and sociodemographic variables in unmatched and matched case-control studies

\begin{tabular}{|c|c|c|c|c|}
\hline \multirow[t]{2}{*}{ Variables } & \multicolumn{2}{|c|}{ Unmatched case-control study } & \multicolumn{2}{|c|}{ Matched case-control study } \\
\hline & OR & p-value & OR & $p$-value \\
\hline \multicolumn{5}{|l|}{ Selected variables, final model } \\
\hline Age as of year $2008^{a}$ & 1.030 & 0.007 & - & - \\
\hline BMI in year 2008 & 1.200 & $<0.001$ & 1.277 & $<0.001$ \\
\hline Exercise & 2.285 & 0.221 & 2.571 & 0.158 \\
\hline History of illness in parents ${ }^{a}$ & 2.119 & 0.046 & - & - \\
\hline History of illness in siblings & 2.913 & 0.010 & 5.846 & 0.005 \\
\hline Smoke (ever smoked?) & - & - & 4.440 & 0.181 \\
\hline Drinking (ever drank?) & 3.363 & 0.028 & 5.000 & 0.197 \\
\hline Govt (Ref laborer and others) ${ }^{b}$ & - & - & 0.376 & 0.131 \\
\hline Motorcar ownership (including motorcycle) & 0.312 & 0.131 & 0.207 & 0.018 \\
\hline
\end{tabular}

Notes: anly unmatched. 'Only matched. - means result is not available because the variable was not included in the analysis model.

Abbreviations: DM, diabetes mellitus; OR, odds ratio; BMI, body mass index; Govt, government officers/business owners; Ref, reference.

Table 2 Descriptive information on arsenic concentration $(\mathrm{mg} / \mathrm{L})$ in different water types and water used for consumption in years 2000 and 2008 of unmatched and matched case-control studies

\begin{tabular}{|c|c|c|c|c|c|c|c|c|}
\hline \multirow{2}{*}{$\begin{array}{l}\text { Arsenic level in water } \\
\text { variables }\end{array}$} & \multicolumn{4}{|c|}{ Unmatched case-control study } & \multicolumn{4}{|c|}{ Matched case-control study } \\
\hline & Mean & SD & Min & Max & Mean & SD & Min & Max \\
\hline \multicolumn{9}{|c|}{ Arsenic level $(\mathrm{mg} / \mathrm{L})$ in different water types in year 2000} \\
\hline Municipal tap & 0.0058 & 0.0049 & 0.0009 & 0.0110 & 0.0057 & 0.0049 & 0.0009 & 0.0110 \\
\hline Well & 0.5383 & 0.7636 & 0.0009 & 8.5830 & 0.5176 & 0.7619 & 0.0009 & 8.5830 \\
\hline Village tap & 0.0402 & 0.0413 & 0.0009 & 0.0920 & 0.0421 & 0.0439 & 0.0009 & 0.0980 \\
\hline Rain & 0.0217 & 0.0304 & 0.0009 & 0.0730 & 0.0173 & 0.0277 & 0.0009 & 0.0730 \\
\hline Bottled $^{a}$ & 0.0000 & 0.0000 & 0.0000 & 0.0000 & 0.0000 & 0.0000 & 0.0000 & 0.0000 \\
\hline \multicolumn{9}{|c|}{ Arsenic level $(\mathrm{mg} / \mathrm{L})$ in different water types in year 2008} \\
\hline Municipal tap & 0.0281 & 0.0426 & 0.0009 & 0.1120 & 0.0307 & 0.0429 & 0.0009 & 0.1050 \\
\hline Well & 0.1214 & 0.1350 & 0.0009 & 0.3290 & 0.2264 & 0.2923 & 0.0009 & 1.1070 \\
\hline Village tap & 0.0605 & 0.0588 & 0.0009 & 0.1500 & 0.0808 & 0.0915 & 0.0009 & 0.2470 \\
\hline Rain & 0.0217 & 0.0304 & 0.0009 & 0.0730 & 0.0173 & 0.0277 & 0.0009 & 0.0730 \\
\hline Bottled $^{\mathrm{a}}$ & 0.0000 & 0.0000 & 0.0000 & 0.0000 & 0.0000 & 0.0000 & 0.0000 & 0.0000 \\
\hline \multicolumn{9}{|c|}{ Arsenic level $(\mathrm{mg} / \mathrm{L})$ of water used for consumption in year 2000} \\
\hline Drinking & 0.0125 & 0.0208 & 0.0000 & 0.0670 & 0.0143 & 0.0225 & 0.0000 & 0.0670 \\
\hline Cooking & 0.1532 & 0.3055 & 0.0000 & 1.0700 & 0.1010 & 0.1954 & 0.0000 & 1.0700 \\
\hline Teeth brushing & 0.2772 & 0.3613 & 0.0000 & 1.3510 & 0.3685 & 0.4646 & 0.0000 & 1.3510 \\
\hline \multicolumn{9}{|c|}{ Arsenic level $(\mathrm{mg} / \mathrm{L})$ of water used for consumption in year 2008} \\
\hline Drinking & 0.0495 & 0.0551 & 0.0000 & 0.1410 & 0.0433 & 0.0509 & 0.0000 & 0.1410 \\
\hline Cooking & 0.1532 & 0.3055 & 0.0000 & 1.0700 & 0.0395 & 0.0497 & 0.0000 & 0.1410 \\
\hline Teeth brushing & 0.0964 & 0.0951 & 0.0009 & 0.3020 & 0.1873 & 0.2224 & 0.0009 & 0.7270 \\
\hline
\end{tabular}

Note: aPresumed, not measured.

Abbreviations: SD, standard deviation; Min, minimum; Max, maximum.

age (unmatched), BMI, and having a history of illness in a sibling were associated with increased DM type 2 risk. In the unmatched group, we observed a significant positive association between DM and having a history of parent illness, whereas in the matched group, we found a significant negative association between DM and motorcar ownership. Living in different Moo Ban, length of residence in this area, skin lesions (having melanosis or hyperkeratosis), marital status (actively married), education, and occupation were not associated with DM type 2 risk (data not shown).

Arsenic concentrations (mg/L or ppm) in different water types and in water used for drinking, cooking, and teeth brushing in both years 2000 and 2008 in both study groups are presented in Table 2. The highest arsenic concentration was found in well water, followed by village tap water, in both years 2000 and 2008 in both groups.

Table 3 lists the results of association analysis after MI between DM type 2 risks and sociodemographic variables and arsenic level in different water type variables in unmatched and matched control groups. In both groups, BMI, having a history of sibling illness, older age (only unmatched), having a history of parent illness (only unmatched), and drinking (only unmatched) were significantly associated with increased DM type 2 risk, whereas exercise and arsenic 
Table 3 Association analysis between selected sociodemographic, arsenic level in water-type variables and DM type 2 risk in unmatched and matched case-control studies

\begin{tabular}{|c|c|c|c|c|c|c|c|c|}
\hline \multirow[t]{3}{*}{ Variables } & \multicolumn{4}{|c|}{ Case-unmatched control study } & \multicolumn{4}{|c|}{ Case-matched control study } \\
\hline & \multirow[t]{2}{*}{ OR } & \multirow[t]{2}{*}{$p$-value } & \multicolumn{2}{|l|}{$95 \% \mathrm{Cl}$} & \multirow[t]{2}{*}{ OR } & \multirow[t]{2}{*}{ p-value } & \multicolumn{2}{|l|}{$95 \% \mathrm{Cl}$} \\
\hline & & & Lower & Upper & & & Lower & Upper \\
\hline \multicolumn{9}{|c|}{ Selected sociodemographic variables } \\
\hline Age as of year $2008^{a}$ & 1.030 & 0.008 & 1.008 & 1.053 & - & - & - & - \\
\hline BMI in year 2008 & 1.203 & $<0.001$ & 1.124 & 1.288 & 1.293 & $<0.001$ & 1.138 & 1.470 \\
\hline Exercise & 2.304 & 0.233 & 0.500 & 10.622 & 2.778 & 0.198 & $0.54 I$ & 14.26 \\
\hline History of parents illness ${ }^{a}$ & 2.056 & 0.051 & 0.997 & 4.24 & - & - & - & - \\
\hline History of siblings illness & 3.022 & 0.010 & 1.333 & 6.851 & 6.743 & 0.002 & 2.077 & 21.89 \\
\hline Ever smoking ${ }^{\mathrm{b}}$ & - & - & - & - & 5.481 & 0.146 & $0.47 \mathrm{I}$ & 63.82 \\
\hline Ever drinking & 3.430 & 0.032 & I.I37 & 10.35 & 4.967 & 0.217 & 0.298 & 82.86 \\
\hline Govt $^{b}$ & - & - & - & - & 0.373 & 0.155 & 0.096 & 1.453 \\
\hline Motorcar ownership & 0.311 & 0.130 & 0.062 & 1.566 & 0.198 & 0.022 & 0.050 & 0.776 \\
\hline \multicolumn{9}{|c|}{ Arsenic level in different water types in year 2000} \\
\hline Well & 1.027 & 0.577 & 0.934 & 1.130 & 1.034 & 0.647 & 0.894 & 1.196 \\
\hline Rain & 0.023 & 0.830 & 0.000 & $2.1 \times 10^{22}$ & 9.260 & 0.940 & 0.000 & $5.8 \times 10^{26}$ \\
\hline \multicolumn{9}{|c|}{ Arsenic level in different water types in year 2008} \\
\hline Municipal tap & 0.100 & 0.549 & 0.000 & 224.4 & 0.001 & 0.549 & 0.000 & $8.2 \times 10^{7}$ \\
\hline Village tap & 0.564 & 0.858 & 0.001 & 472.5 & 0.690 & 0.894 & 0.002 & 220.1 \\
\hline Rain & 19.370 & 0.875 & 0.000 & $4.1 \times 10^{18}$ & 0.737 & 0.992 & 0.000 & $3.6 \times 10^{27}$ \\
\hline
\end{tabular}

Notes: a Only unmatched. ' ${ }^{\circ}$ nly matched. - means result is not available because the variable was not included in the analysis model; for government employers or business owner variable, laborers/others was used as reference.

Abbreviations: DM, diabetes mellitus; OR, odds ratio; Cl, confidence interval; BMI, body mass index; Govt, government officers or business owners.

level in all types of water, in both years, were not. Owning a motorcar (including motorcycle) was significantly associated with lower DM type 2 risk only in the matched group. $p$-Values were consistently large for all arsenic metrics considered, indicating no appreciable associations in this data set between arsenic level and diabetes risk.

Table 4 presents the results of association analysis between DM type 2 risk and selected demographic variables; arsenic level of water used for consumption (drinking, cooking, and teeth brushing/bathing) in years 2000 and 2008 variables in unmatched and matched case-control groups. Among the input variables in the constructed model of both groups, BMI, having a history of illness in siblings, and drinking were found to be statistically significantly associated with increased DM type 2 risk, whereas exercise and arsenic concentration in water used for drinking, cooking, and teeth brushing/bathing were not. It was also found that age and having a history of illness in parents in the unmatched group were significantly associated with higher DM type 2 risk, whereas these two variables were not included in the matched model analysis. Motorcar ownership variable showed a strong significant association with lower DM type 2 risk in the matched group ( $p=0.015$, odds ratio $[\mathrm{OR}]=0.183$ ). $p$-values were consistently large for all arsenic metrics considered, indicating no appreciable associations in this data set between arsenic level and diabetes risk.

\section{Discussion}

Similar to previous studies worldwide, we consistently found that BMI was associated with increased DM type 2 risk. ${ }^{2,5,13,14}$ Physical inactivity is considered as a DM type 2 risk factor. ${ }^{13,14}$ Exercise was associated, though not significantly, with increased DM type 2 risk in all categories of modeling in this study. Further research is still required to ascertain the true relationship between exercise and DM type 2 risk in this study area. We also found that a history of illness in siblings was significantly associated with increased DM type 2 risk in both unmatched and matched control groups in every constructed model, which is similar to the result reported previously. ${ }^{6,13}$

In the unmatched control group, we found that drinking was consistently positively and significantly associated with DM type 2 risk, whereas an inverse association was identified for owning a motorcar, representing better economic status in the matched study. Further study on the effects of synergistic interaction between arsenic exposure at low-to-moderate dose and smoking and drinking on DM type 2 is needed.

We did not find association between smoking and DM type 2 risk in either the unmatched or matched studies. Chen et $\mathrm{l}^{15}$ observed a synergistic effect on ischemic heart disease of individuals after exposure to both cigarette smoking and arsenic at concentrations as low as $25.3-114.0 \mu \mathrm{g} / \mathrm{L}$. Results from a case-control study in Bangladesh to investigate the 
Table 4 Association analysis between selected sociodemographic, water arsenic level metric variables and DM type 2 risk in unmatched and matched case-control studies

\begin{tabular}{|c|c|c|c|c|c|c|c|c|}
\hline \multirow[t]{3}{*}{ Variables } & \multicolumn{4}{|c|}{ Case-unmatched control groups } & \multicolumn{4}{|c|}{ Case-matched control groups } \\
\hline & \multirow[t]{2}{*}{ OR } & \multirow[t]{2}{*}{$p$-value } & \multicolumn{2}{|l|}{$95 \% \mathrm{Cl}$} & \multirow[t]{2}{*}{ OR } & \multirow[t]{2}{*}{ p-value } & \multicolumn{2}{|l|}{$95 \% \mathrm{Cl}$} \\
\hline & & & Lower & Upper & & & Lower & Upper \\
\hline \multicolumn{9}{|l|}{ Selected sociodemographic variables } \\
\hline Age as of year $2008^{a}$ & 1.030 & 0.008 & 1.008 & 1.053 & - & - & - & - \\
\hline BMI in year 2008 & 1.203 & $<0.001$ & $\mathrm{I} .124$ & $\mathrm{I} .288$ & 1.290 & $<0.001$ & 1.135 & 1.466 \\
\hline Exercise & 2.270 & 0.214 & 0.548 & 9.403 & 2.728 & 0.196 & 0.552 & 13.48 \\
\hline Having history of illness in parents ${ }^{a}$ & 2.201 & 0.049 & 1.004 & 4.822 & - & - & - & - \\
\hline Having history of illness in siblings & 2.955 & 0.011 & 1.312 & 6.656 & 6.560 & 0.005 & 1.813 & 23.73 \\
\hline Ever smoking ${ }^{\mathrm{b}}$ & - & - & - & - & 4.648 & 0.204 & 0.344 & 62.76 \\
\hline Ever drinking & 3.327 & 0.032 & $\mathrm{I} .134$ & 9.760 & 5.230 & 0.198 & 0.328 & 83.43 \\
\hline Govt $^{\mathrm{b}}$ & - & - & - & - & 0.375 & 0.144 & 0.100 & 1.398 \\
\hline Motorcar ownership & 0.309 & 0.120 & 0.064 & 1.493 & 0.183 & 0.015 & 0.048 & 0.699 \\
\hline \multicolumn{9}{|c|}{ Arsenic level of water used for consumption in year 2000 variables } \\
\hline Drinking & 3.220 & 0.890 & 0.000 & $3.2 \times 10^{8}$ & $7.54 I$ & 0.824 & 0.000 & $5.9 \times 10^{8}$ \\
\hline Cooking & 1.049 & 0.960 & 0.150 & 7.339 & 1.221 & 0.884 & 0.075 & 19.99 \\
\hline Teeth brushing & 0.840 & 0.777 & 0.221 & 3.192 & 0.975 & 0.972 & 0.218 & 4.358 \\
\hline \multicolumn{9}{|c|}{ Arsenic level of water used for consumption in year 2008 variables } \\
\hline Drinking & 1.482 & 0.889 & 0.005 & 406 & 4.304 & 0.730 & 0.001 & $2.0 \times 10^{4}$ \\
\hline Cooking & 0.043 & 0.202 & 0.000 & 5.483 & 0.209 & 0.768 & 0.000 & $1.7 \times 10^{4}$ \\
\hline Teeth brushing & 0.626 & 0.805 & 0.011 & 34.95 & 0.499 & 0.758 & 0.003 & 71.63 \\
\hline
\end{tabular}

Notes: ${ }^{a}$ Only unmatched. 'Only matched. - means result is not available because the variable was not included in the analysis model; for government employers or business owner variable, laborers/others was used as reference.

Abbreviations: DM, diabetes mellitus; OR, odds ratio; Cl, confidence interval; BMI, body mass index; Govt, government officers or business owners.

association between DM type 2 and moderate dose of arsenic exposure suggested that being overweight, smoking, and arsenic exposure increased the risk of DM type $2 .{ }^{16}$

We combined selected sociodemographic variables (being male, age in year 2008, BMI in year 2008, exercise, having a history of illness in parents, having a history of illness in siblings, drinking, and having a motorcar for the unmatched control group and BMI in year 2008, exercise, having a history of illness in siblings, smoking, drinking, being government official or having own business, having a motorcar for the matched control group) with different sets of arsenic-related metric variables in the constructed model for association analysis. These arsenic-related metrics include: 1) sets of arsenic concentrations in each water type in both years 2000 and 2008 and 2) sets of arsenic concentrations in water used for drinking, cooking, and teeth brushing/bathing in years 2000 and 2008.

Similar to those reported in Bangladesh, average concentrations of arsenic in different water types and water used for drinking, cooking, and teeth brushing/bathing in years 2000 and 2008 were consistently not significantly associated with the risk of DM type 2 in both of our studied groups. In a population-based cross-sectional study in Bangladesh, Chen et $\mathrm{al}^{7}$ observed no association between arsenic exposure (used arsenic in well water and total arsenic in urine as indicators of exposure) and DM (used glucosuria and HbA1c [blood glycosylated hemoglobin] as indicators of effect). In the subsequent prospective cohort study to evaluate the association between arsenic exposure and cardiovascular diseases, an adverse association between arsenic exposure via drinking water and mortality from heart disease, especially among smokers, was observed..$^{15}$ However, there are a number of studies that reported the association between DM and low-dose arsenic exposure (mainly in drinking water). For example, in a casecohort study on the association between DM risk and lifetime exposure to low levels of inorganic arsenic in the US, it was found that for every $15 \mathrm{mg} / \mathrm{L}$ increase in arsenic concentration in drinking water, the risk for DM increased by $27 \%(95 \%$ confidence interval $[\mathrm{CI}]=1-59$ ) after adjusting for ethnicity, time varying measures of BMI, and physical activity. ${ }^{17}$ In a community-based case-control study in Mexico, after adjusting for potential confounding variables such as gender, age, triglycerides, body mass index, HT, a family history of $\mathrm{DM}$, and using tertiles distribution of arsenic in urine as a cutoff point in the model, Coronado-González et a ${ }^{1}$ reported that the higher risk of DM type 2 was related to age, being female, and the presence of high blood pressure as well as urinary total arsenic level. So far, although many research groups had tried to establish prospective case-cohort study, a causal relationship between low-dose arsenic exposure and 
DM type 2 could not be established, and limited sample size was found to be the major limitation. ${ }^{18}$

Arsenic level in water used for teeth brushing/bathing was highest in the year 2000 in both groups $(0.2772 \mathrm{mg} / \mathrm{L}$, unmatched; $0.3685 \mathrm{mg} / \mathrm{L}$, matched). In year 2008, the highest mean arsenic levels were found in water used for cooking $(0.1532 \mathrm{mg} / \mathrm{L})$ in the unmatched group, whereas in the matched group, it was evidenced in water used for teeth brushing/bathing $(0.1873 \mathrm{mg} / \mathrm{L})$.

We did not directly measure consumption rate (gram of water per person per day) of drinking, cooking, and oral-accidental source of teeth brushing water and arsenic concentration in food consumed by each individual in studies of both years 2000 and 2008. To calculate individual arsenic dose (microgram arsenic per kilogram body weight per day), it would have been necessary to make multiple assumptions. In our opinion, this would have introduced undue uncertainty into the calculations, even though the calculations that we used were subject to some uncertainty themselves.

\section{Strength of this study}

This study has the strongest point of the arsenic exposure estimation via the availability of good arsenic concentration data and the questionnaire response regarding purpose of use of each water type for both years 2000 and 2008 . This allowed us to specify exposed arsenic concentration at the individual level according to the purpose of use. Water samples were analyzed in accredited laboratories (certified ISO17025) of the Department of Medical Sciences; thus, the quality of arsenic concentration results was ensured. All related data were collected by trained personnel according to developed guidelines.

\section{Limitations and uncertainties}

In this study, some limitations with missing data exist. To reduce risk of bias caused by inappropriate handling of missing data, ${ }^{19}$ the MI technique attached in SPSS v22.0 (IBM) was used. The PMM, as an imputation method in the method subcommand of MI, SPSS version 22.0, was selected to prevent negative value after MI of quantitative variables that were not normally distributed. ${ }^{12}$ Unavoidable uncertainty could occur due to indirect measurement of exposure level; in fact, we measured arsenic level in water in each household. We also made the following assumptions in the estimation of arsenic-exposed level in water, and this could contribute to manageable uncertainties:
- We considered ingestion of arsenic-contaminated water as the route of exposure in this study. Skin absorption of arsenic contaminated water via bathing is negligible. Villagers did not use bathtub when taking a bath, according to results of field observation during house visits in the study of year 2000. They used cement or plastic tanks or earth jars to collect water for bathing and teeth brushing and used a bowl to shower. They also brushed their teeth while bathing in the morning and evening. By this practice, the amount of water they used was too little and the contact time was too short to cause any effective absorption. However, teeth brushing water is considered as oral-accidental exposure source instead.

- For arsenic concentration in rain water, we used results of the year 2000 study in year 2008 as well, assuming that rain water collected from each household in the study area in the year 2000 study should not be significantly different from that of the year 2008 (where rain water was not collected).

- The intake of arsenic from food was not considered, although water used for cooking was considered. We did not investigate consumption of seafood of individuals, even though it could be considered as another source of arsenic exposure.

\section{Conclusion}

The findings regarding sociodemographic information of both control groups confirm that older age (only unmatched), BMI, and having a history of illness in siblings were associated with higher DM type 2 risk. Our analysis suggested no convincing association of water arsenic concentration with diabetes risk in both unmatched and matched control studies. Having a history of illness in parents and drinking were associated with a higher DM type 2 risk in the unmatched group, whereas motorcar ownership (representing better economic status) was associated with a lower risk of DM in the matched study.

Multidisciplinary team of family doctors responsible for the Ron Phibun district should be equipped with this message of DM risk determinants when they plan to visit households and work in this area.

Finally, in additional analyses (data not shown), we observed a marginally negative association between rain water use and diabetes risk $(\mathrm{OR}=0.517, p=0.054$ in the unmatched study; $\mathrm{OR}=0.406, p=0.094$ in the matched study). Because arsenic levels in rain water are relatively low, there may actually be a limited positive association between arsenic and diabetes risk in the study area. This observation warrants 
further research on the relationship between environmental arsenic and diabetes risk in the study area and elsewhere in Thailand.

\section{Acknowledgments}

This research was supported by the Royal Thai Government under the Department of Medical Sciences (for studies of years 2000 and 2008) and the EU funds for the project "The Mechanistic Basis for Providing a Realistic Cancer Risk Assessment for Exposure to Inorganic Arsenic within the EU Community" (during the study of year 2000). We would like to thank all the health volunteers and the Ron Phibun people for their cooperation. We appreciate the cooperative effort of staff members of Ron Phibun Hospital for allowing us to use their network and supporting facilities to collect all necessary information. We are grateful to all the villagers in Moo 2, 12, and 13 of Ron Phibun subdistrict, who allowed us and the team to work in their villages, walking around their houses and kitchens to collect water samples, and answering our questions during those years. We are grateful for the contribution of laboratory staff from Trang and Surat Thanee Regional Medical Sciences Centre, Department of Medical Sciences, Thailand.

\section{Author contributions}

All authors made substantial contributions to conception and design, acquisition of data, analysis and interpretation of data; took part in drafting the article or revising it critically for important intellectual content; gave final approval of the version to be published; and agree to be accountable for all aspects of the work.

\section{Disclosure}

The authors report no conflicts of interest in this work.

\section{References}

1. Coronado-González JA, Del Razo LM, García-Vargas G, SanmiguelSalazar F, Escobedo-de la Peña J. Inorganic arsenic exposure and type 2 diabetes mellitus in Mexico. Environ Res. 2007;104(3): 383-389.
2. Tseng C-H, Tai T-Y, Chong C-K, et al. Long-term arsenic exposure and incidence of non-insulin-dependent diabetes mellitus: a cohort study in arseniasis-hyperendemic villages in Taiwan. Environ Health Perspect. 2000;108(9):847.

3. Rahman M, Tondel M, Chowdhury IA, Axelson O. Relations between exposure to arsenic, skin lesions, and glucosuria. Occup Environ Med. 1999;56(4):277-281.

4. Lai M-S, Hsueh Y-M, Chen C-J, et al. Ingested inorganic arsenic and prevalence of diabetes mellitus. Am J Epidemiol. 1994;139(5):484-492.

5. Navas-Acien A, Silbergeld EK, Streeter RA, Clark JM, Burke TA, Guallar E. Arsenic exposure and type 2 diabetes: a systematic review of the experimental and epidemiologic evidence. Environ Health Perspect. 2006;114(5):641-648.

6. Chen C-J, Wang S-L, Chiou J-M, et al. Arsenic and diabetes and hypertension in human populations: a review. Toxicol Appl Pharmacol. 2007;222(3):298-304.

7. Chen Y, Ahsan H, Slavkovich V, et al. No association between arsenic exposure from drinking water and diabetes mellitus: a cross-sectional study in Bangladesh. Environ Health Perspect. 2010;118(9):1299.

8. Sung T-C, Huang J-W, Guo H-R. Association between arsenic exposure and diabetes: a meta-analysis. Biomed Res Int. 2015;2015:368087.

9. Williams M, Fordyce F, Paijitprapapon A, Charoenchaisri P. Arsenic contamination in surface drainage and groundwater in part of the southeast Asian tin belt, Nakhon Si Thammarat Province, southern Thailand. Environ Geol. 1996;27(1):16-33.

10. Fry RC, Navasumrit P, Valiathan C, et al. Activation of inflammation/ $\mathrm{NF}-\mathrm{\kappa B}$ signaling in infants born to arsenic-exposed mothers. PLoS Genet. 2007;3(11):e207.

11. Pavittranon S, Sripaoraya K, Ramchuen S, et al. Laboratory case identification of arsenic in Ronpibul village, Thailand (2000-2002). J Environ Sci Health A Tox Hazard Subst Environ Eng. 2003;38(1):213-221.

12. Allison PD. Multiple imputation for missing data: a cautionary tale. Sociological Methods \& Research. 2000;28(3):301-309.

13. Longnecker MP, Daniels JL. Environmental contaminants as etiologic factors for diabetes. Environ Health Perspect. 2001;109(suppl 6):871.

14. Meliker JR, Wahl RL, Cameron LL, Nriagu JO. Arsenic in drinking water and cerebrovascular disease, diabetes mellitus, and kidney disease in Michigan: a standardized mortality ratio analysis. Environ Health. 2007;6(1):1.

15. Chen Y, Graziano JH, Parvez F, et al. Arsenic exposure from drinking water and mortality from cardiovascular disease in Bangladesh: prospective cohort study. BMJ. 2011;342:d2431.

16. Pan W-C, Seow WJ, Kile ML, et al. Association of low to moderate levels of arsenic exposure with risk of type 2 diabetes in Bangladesh. Am J Epidemiol. 2013;178(10):1563-1570.

17. James KA, Marshall JA, Hokanson JE, Meliker JR, Zerbe GO, Byers TE. A case-cohort study examining lifetime exposure to inorganic arsenic in drinking water and diabetes mellitus. Environ Res. 2013;123:33-38.

18. Kuo C-C, Moon K, Thayer KA, Navas-Acien A. Environmental chemicals and type 2 diabetes: an updated systematic review of the epidemiologic evidence. Curr Diab Rep. 2013;13(6):831-849.

19. Sterne JA, White IR, Carlin JB, et al. Multiple imputation for missing data in epidemiological and clinical research: potential and pitfalls. BMJ. 2009;338:b2393.
Risk Management and Healthcare Policy

Publish your work in this journal

Risk Management and Healthcare Policy is an international, peer-reviewed, open access journal focusing on all aspects of public health, policy, and preventative measures to promote good health and improve morbidity and mortality in the population. The journal welcomes submitted papers covering original research, basic science, clinical and epidemiological

\section{Dovepress}

studies, reviews and evaluations, guidelines, expert opinion and commentary, case reports and extended reports. The manuscript management system is completely online and includes a very quick and fair peerreview system, which is all easy to use. Visit http://www.dovepress.com/ testimonials.php to read real quotes from published authors. 